\begin{tabular}{|c|c|c|}
\hline BENTHAM OPEN & The Open Civil Engineering Journal & $\begin{array}{l}\text { The Open } \\
\text { Crill } \\
\text { loungher }\end{array}$ \\
\hline CrossMark & Content list available at: www.benthamopen.com/TOCIEJ/ & 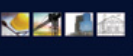 \\
\hline & DOI: $10.2174 / 1874149501610010461$ & \\
\hline
\end{tabular}

RESEARCH ARTICLE

\title{
Research on Critical Effusion Volume for the China-Burma Natural Gas Pipeline
}

\author{
Xiyao Liu ${ }^{1}$, Changjun $\mathrm{Li}^{1,{ }^{*}}$, Yang Peng ${ }^{1}$, Yanjie $\mathrm{Jia}^{2}$ and Chunqing $\mathrm{Li}^{2}$

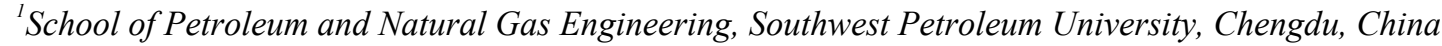 \\ ${ }^{2}$ CNPC Southwest Pipeline Co. Ltd., Chengdu, China
}

Received: November 25, 2015

Revised: March 14, 2016

Accepted: May 11, 2016

\begin{abstract}
Under certain temperature and pressure conditions, natural gas condensates and the liquid is accumulated in the pipeline during transmission of gas. It is therefore important to calculate the critical effusion volume accurately so that a reasonable pigging cycle can be determined. Frequent pigging operation not only affects the normal gas supply, but also causes unpiggable obstacles. This study has developed a liquid prediction model in which the effusion volume is dependent on the liquid holdup and the capacity of the gas to carry liquid. Using the analysis software OLGA and applying the model to the China-Burma pipeline, the critical effusion volume and the parameters distribution curves along the pipeline have been determined. The results show that the critical effusion volume in the pipeline decreases with increasing throughput. The method is a significant advancement in determining the pigging cycle and mitigating the pigging risk.
\end{abstract}

Keywords: Accumulated liquid, Critical effusion volume, Natural gas condensate, OLGA, Pipeline, Throughput.

\section{INTRODUCTION}

The pipeline from Burma to China is a strategic pipeline for importing natural gas to southwest China, such as the city of Ruili in Yunnan province, China. The pipeline has been laid following the terrain of the rolling mountains in Yunnan province. Thus, the pipeline has an undulating profile. Considering the heat exchange between the pipeline wall and the surrounding environment during the transmission of gas, the temperature of the internal fluid is generally lower. Under certain temperature and pressure conditions, the natural gas condensates and the liquid is accumulated at the low points of the pipeline. The accumulated liquid in the pipeline is shown in Fig. (1). The existence of effusion reduces the cross-sectional area of the pipeline for gas flow thereby causing a higher energy consumption, higher pressure drop, and lower delivery ability [1]. In addition, effusion subjects the gas pipeline to two-phase flow which affects its operational modality and the associated peripheral facilities.

In the petroleum and gas industry, pigging operation is a common practice to remove the pipeline effusion and keep the pipeline free of liquid.

However, before a reasonable pigging cycle can be determined, the pipeline effusion volume must be accurately predicted first. An inappropriate pigging cycle not only affects the normal gas supply, it also causes unpiggable obstacles and building up of pressure [2]. In addition, the pigging causes the pipe wall to be worn out, which poses a great potential risk during the pigging process. In view of all these, it is therefore imperative to develop a liquid model which can predict the critical effusion volume accurately.

\footnotetext{
* Address correspondence to this author at the School of Petroleum and Natural Gas Engineering, Southwest Petroleum University, Chengdu, China; E-mail: 350378817@qq.com
} 


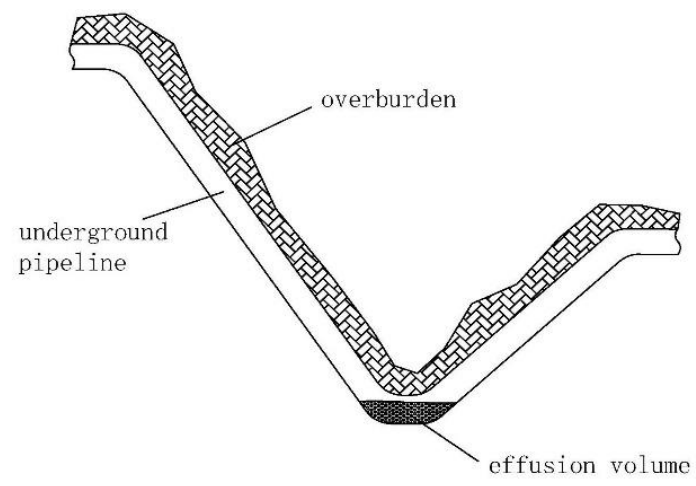

Fig. (1). The accumulated liquid in the pipeline.

The issue of effusion in natural gas pipeline on hilly terrain has been becoming more prominent. In recent years, there have been many domestic and foreign researchers studying the pigging cycle in two-phase flow pipelines [3, 4]. However, for undulating pipelines, it is difficult to predict the critical effusion volume accurately. In view of this, this study uses the two-phase flow theory and the OLGA analysis software (which is a dynamic, one-dimensional, extend two-fluid model), to calculate the critical effusion volume in the China-Burma natural gas pipeline for different flow conditions $[5,6]$. Further, based on the calculated distribution curves of temperature, pressure, holdup and critical effusion volume, the pigging cycle can be determined.

\section{MODEL OF EFFUSION}

\subsection{Progress of Calculating Effusion Volume}

Due to the heat exchange between the pipeline wall and the surrounding environment, both the temperature and pressure of the natural gas decrease. Under certain temperature and pressure conditions, natural gas condensates and the liquid is accumulated at the low points of the pipeline, which becomes part of the two-phase flow. If the parameters of the liquid holdup in the pipeline are known, the effusion volume can be calculated, as follows:

$$
Q_{L_{x}}=\int_{0}^{L_{x}} H_{L} \times A \times d_{L}
$$

In Eq. 1, $Q_{\mathrm{Lx}}=$ the total effusion volume in the length $L_{\mathrm{x}}, L_{\mathrm{x}}=$ the distance from inlet of the pipe to the point of calculation, $H_{\mathrm{L}}=$ liquid holdup, $A=$ cross-sectional of the pipe area, $d_{\mathrm{L}}=$ infinitesimal length.

The liquid holdup mainly depends on two parameters: (1) the volume of condensed liquid, and (2) the capacity of the gas to carry liquid. In general, the volume of condensed liquid can be calculated using the phase equilibrium model according to the temperature and pressure along the pipeline. Based on the flow regime, the volume of liquid carried by the gas can be calculated using a hydraulic model. The capacity of the gas to carry liquid is mainly dependent on throughput. With an increase in throughput, the faster the gas velocity, and the shear force between the liquid and the gas increases. So, some liquid is carried out of the pipe and the effusion volume decreases.

In order to calculate the effusion volume, first, divide the pipe into multiple cells and calculate the temperature and pressure along the pipeline. This is to determine whether there is liquid condensation according to the equation of phase equilibrium. If there is liquid condensation, the condensation causes the flow in the gas pipeline to become two-phase. If there is no liquid condensation in the pipe, then the liquid holdup is zero. The flow regime can then be determined according to the gas and liquid flow rates. Based on the flow regime, an appropriate hydraulic model is chosen to calculate the liquid holdup. Finally, Eq. 1 is used to calculate the effusion volume from the pipe inlet to the pipe outlet.

\subsection{Phase Equilibrium Model}

The volume of liquid condensation mainly depends on the temperature and pressure in the pipeline. It is therefore important to determine the relationship between the temperature and the pressure. At present, BWRST is one of the 
most accurate state equations to determine the relationship of PVT for different flow conditions. The BWRST state equation uses 11 parameters to describe the relationship of PVT [7]. Therefore, this study uses the BWRST state equation to calculate the phase equilibrium and physical property.

\subsection{Hydraulic Model}

In this study, according to the field data of the two-phase flow, the flow regime is stratified flow. Therefore, the stratified flow hydraulic model has been used to calculate the capacity of the gas to carry liquid, as shown in Figs. ( 2 and 3).

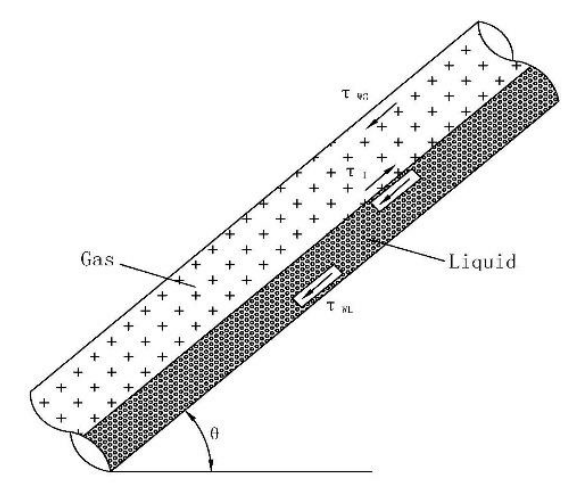

Fig. (2). The hydraulic model of stratified flow.

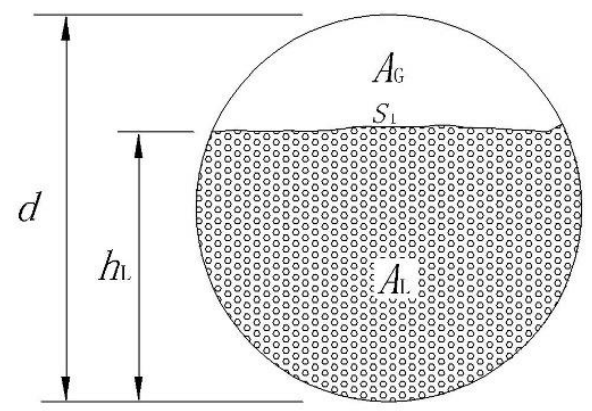

Fig. (3). Cross-sectional areas of stratified flow in a pipeline.

The momentum balances on the liquid film and the gas core yield:

$$
\begin{aligned}
& -A_{L} \frac{d P}{d x} g-\tau_{w L} S_{L} g+\tau_{I} S_{I} g-\rho_{L} A_{L} g \sin \theta=0 \\
& -A_{G} g \frac{d P}{d x}-\tau_{w G} S_{G} g-\tau_{I} S_{I} g-\rho_{G} A_{G} g \sin \theta=0
\end{aligned}
$$

In Eqs. 2-3, $A_{\mathrm{L}}, A_{\mathrm{G}}=$ cross-sectional area of gas phase, cross-section area of liquid phase. $S_{\mathrm{L}}, S_{\mathrm{G}}, S_{\mathrm{I}}=$ wetted perimeter of liquid phase, wetted perimeter of gas phase, the length of gas-liquid interface. $\tau_{\mathrm{WL}} 、 \tau_{\mathrm{WG}} 、 \tau_{\mathrm{I}}=$ the shear force between pipe wall and liquid phase, the shear force between pipe wall and gas phase, the shear force between gas phase and liquid phase. Details of the parameters and their and reference values can be found in publications [8 - 10].

Using Eqs. 2 and 3, Eq. 4 can be derived, as follows:

$$
\tau_{w L} \frac{S_{L}}{A_{L}}-\tau_{W G} \frac{S_{G}}{A_{G}}-\tau_{I} S_{I}\left\lfloor\frac{1}{A_{L}}+\frac{1}{A_{G}}\right\rfloor+\left(\rho_{L}-\rho_{G}\right) g \sin \theta=0
$$


Since the five parameters, $A_{\mathrm{L}}, A_{\mathrm{G}}, S_{\mathrm{L}}, S_{\mathrm{G}}$, and $S_{\mathrm{I}}$, are dependent on the gas-liquid interface height, $h_{\mathrm{L}}$, and $h_{\mathrm{L}}$ can be determined using an iterative method, the liquid holdup can be calculated, as follows:

$$
H_{L}=\frac{\pi-\cos ^{-1}\left(2 \frac{h_{L}}{d}-1\right)+\left(2 \frac{h_{L}}{d}-1\right) \times \sqrt{-\left(2 \frac{h_{L}}{d}-1\right)^{2}}}{\pi}
$$

\section{APPLICATION OF THE MODEL}

Taking the China-Burma natural gas pipeline in Yunnan province as the example. Details of the pipeline are shown in Table 1. Fig. (5) shows the elevation and length along the pipeline.

Table 1. The pipeline operating data.

\begin{tabular}{|c|c|}
\hline Parameters & Value \\
\hline Length & $250 \mathrm{~km}$ \\
\hline Diameter & $1016 \mathrm{~mm}$ \\
\hline Wall thickness & $17.5 \mathrm{~mm}$ \\
\hline Pipe material & API X80 \\
\hline Wall roughness & $0.02 \mathrm{~mm}$ \\
\hline Surrounding temperature & $6^{\circ} \mathrm{C}$ \\
\hline Total thermal conductivity & $1.5 \mathrm{~W} / \mathrm{m}^{2} \cdot \mathrm{K}$ \\
\hline Flow rate at input & $1000 \sim 3500\left(10^{4} \mathrm{~m}^{3} / \mathrm{d}\right)$ \\
\hline Temperature at input & $21^{\circ} \mathrm{C}$ \\
\hline Pressure at input & $6.5 \mathrm{MPa}$ \\
\hline
\end{tabular}

The multiphase flow dynamic simulation software, OLGA, has been used to model the two-phase flow. So, using OLGA, the critical effusion volume has been calculated by inputting the pipeline data (Table 1) and the components of the natural gas (Table 2) into effusion model (Fig. 4)

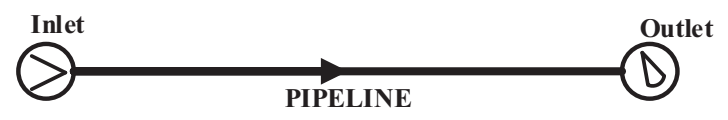

Fig. (4). The established prediction effusion volume model in OLGA.

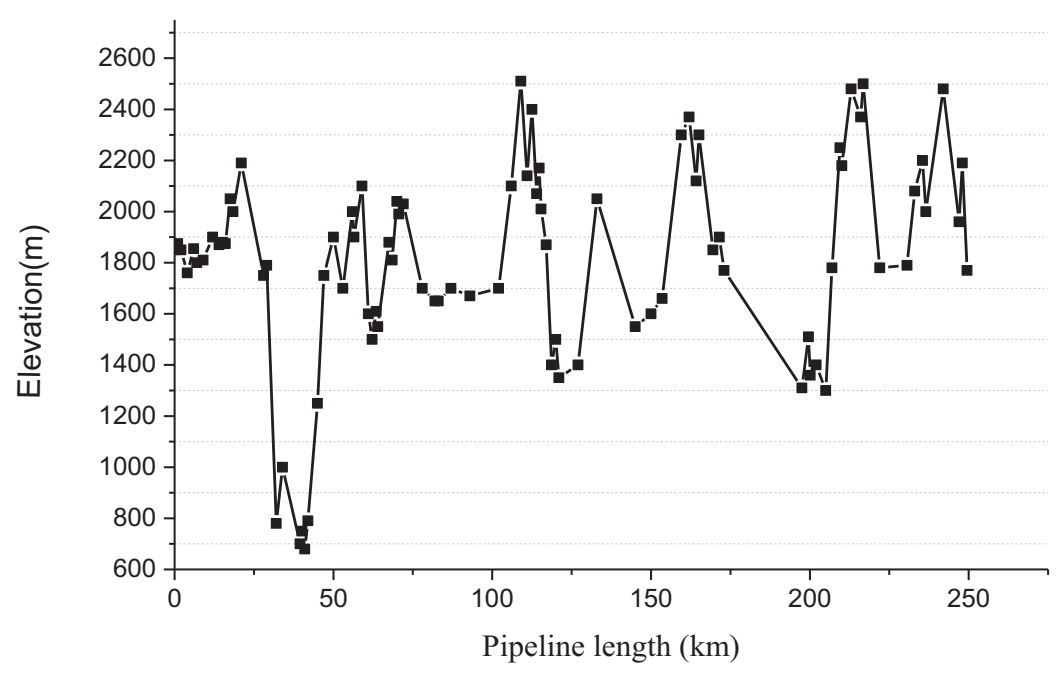

Fig. (5). Elevation and length along the pipeline.

\section{ANALYSIS OF CRITICAL EFFUSION VOLUME FOR DIFFERENT FLOW CONDITONS}

The calculated temperature, pressure, and holdup, for different effusion quantity and flow rates are shown in Figs. (5 
- 11). In these figures, $x$-axis is the distance along the pipeline from the pipe inlet. The four parameters on the $y$-axis are: -ACCLIQBR is the critical effusion volume; HOL is the liquid holdup; PT is the pressure; and TM is the temperature.

Table 2. The components of natural gas.

\begin{tabular}{|c|c|c|c|c|c|c|c|c|c|}
\hline Component & $\mathbf{C H}_{4}$ & $\mathbf{C}_{2} \mathbf{H}_{6}$ & $\mathbf{i}-\mathbf{C}_{4} \mathbf{H}_{10}$ & $\mathbf{n}-\mathbf{C}_{4} \mathbf{H}_{10}$ & $\mathbf{i}-\mathbf{C}_{5} \mathbf{H}_{12}$ & $\mathbf{n}-\mathbf{C}_{5} \mathbf{H}_{12}$ & $\mathbf{C}_{6}^{+}$ & $\mathbf{N}_{2}$ & $\mathbf{C O}_{2}$ \\
\hline $\mathrm{mol} \%$ & 95.49 & 2.16 & 0.084 & 0.0609 & 0.020 & 0.0241 & 0.075 & 0.659 & 1.05 \\
\hline
\end{tabular}

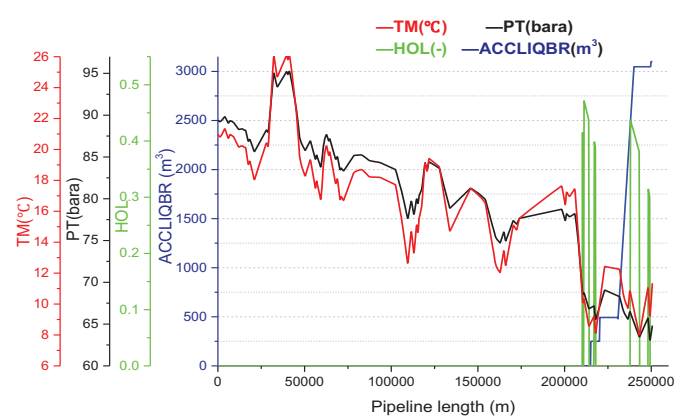

Fig. (6). The pressure, temperature and liquid holdup along the pipeline with $3100 \mathrm{~m}^{3}$ effusion volume and $1000 \times 10^{4} \mathrm{~m}^{3} / \mathrm{d}$ throughput.

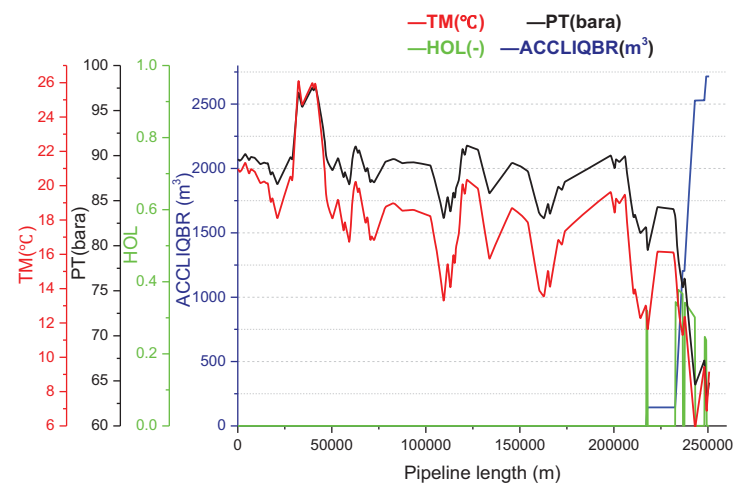

Fig. (7). The pressure, temperature and liquid holdup along the pipeline with $2700 \mathrm{~m}^{3}$ effusion volume and $1500 \times 10^{4} \mathrm{~m}^{3} / \mathrm{d}$ throughput.

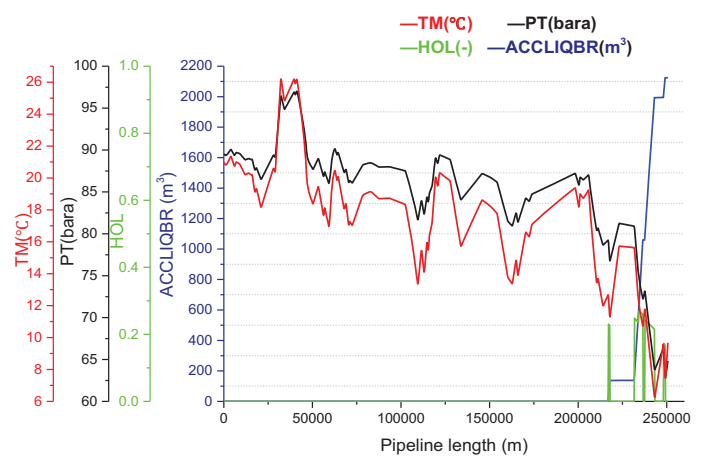

Fig. (8). The pressure, temperature and liquid holdup along the pipeline with $2100 \mathrm{~m}^{3}$ effusion volume and $2000 \times 10^{4} \mathrm{~m}^{3} / \mathrm{d}$ throughput.

As shown in Figs. (5 - 11), the effusion volume in the pipeline is mainly distributed between the distance 200 and $250 \mathrm{~km}$, which is close to the pipe outlet. However, the holdup is zero near the pipe inlet. As the fluid closer to the pipe outlet, the temperature and pressure are at their lowest. Hence, liquid condensation is likely to occur. Further, as the 
inlet temperature is higher than outlet temperature, the holdup and the effusion volume are zero.

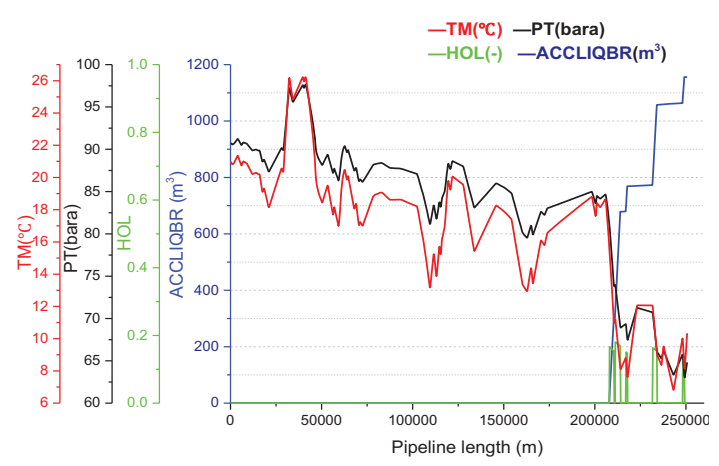

Fig. (9). The pressure, temperature and liquid holdup along the pipeline with $1100 \mathrm{~m}^{3}$ effusion volume and $2500 \times 10^{4} \mathrm{~m}^{3} / \mathrm{d}$ throughput.

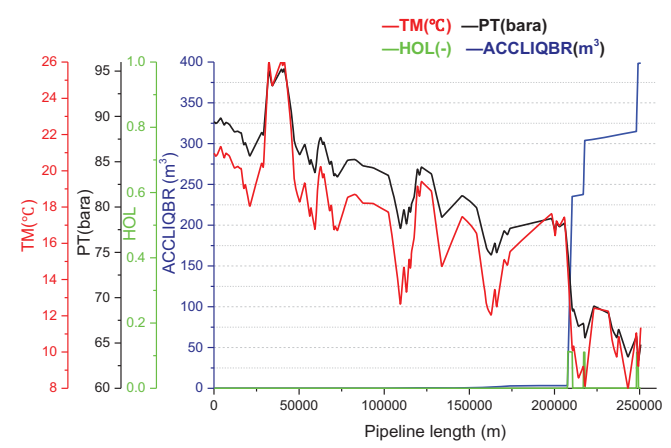

Fig. (10). The pressure, temperature and liquid holdup along the pipeline with $400 \mathrm{~m}^{3}$ effusion volume and $3000 \times 10^{4} \mathrm{~m}^{3} / \mathrm{d}$ throughput.

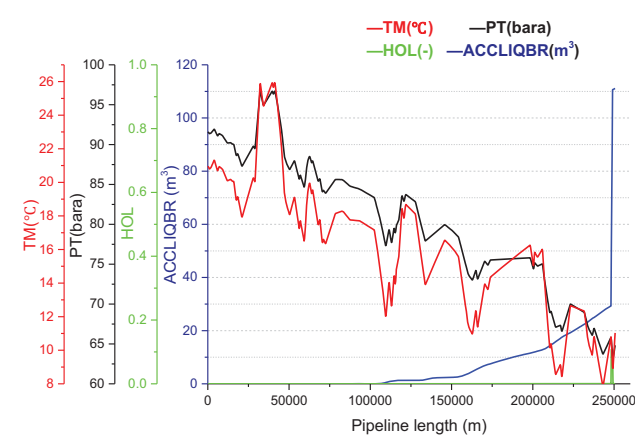

Fig. (11). The pressure, temperature and liquid holdup along the pipeline with $110 \mathrm{~m}^{3}$ effusion volume and $3500 \times 10^{4} \mathrm{~m}^{3} / \mathrm{d}$ throughput.

Further, as shown in Figs. (5 - 11), due to the changing terrain, the pressure of the natural gas pipeline also changes significantly. The maximum pressure is at the distance about $30 \mathrm{~km}$. As the natural gas condensates, the liquid is accumulated at the low points of the pipeline. The accumulated liquid occupies part of the cross-sectional area of the gas pipeline. Consequently, the pressure in the pipeline increases. For larger effusion volume, the pressure in the pipeline is higher. When the pressure in the pipeline is close to the design pressure of $10 \mathrm{MPa}$, the effusion volume is at the maximum. This maximum volume is the critical effusion volume.

Based on Figs. (5 - 11), Table 3 show the critical effusion volume and the maximum pressure in the pipeline for the corresponding throughput. 


\section{DISCUSSION}

Based on Table 3, the relationship between the throughput and the critical effusion volume in the pipeline is shown in Fig. (12).

Table 3. Critical effusion volume and maximum pressure for corresponding throughput.

\begin{tabular}{|c|c|c|}
\hline $\begin{array}{l}\text { Throughput } \\
\left(10^{4} \mathrm{~m} 3 / \mathrm{d}\right)\end{array}$ & Critical effusion volume $\left(\mathrm{m}^{3}\right)$ & Maximum pressure(MPa) \\
\hline 1000 & 3100 & 9.62 \\
\hline 1500 & 2700 & 9.78 \\
\hline 2000 & 2100 & 9.89 \\
\hline 2500 & 1100 & 9.91 \\
\hline 3000 & 400 & 9.52 \\
\hline 3500 & 110 & 9.88 \\
\hline
\end{tabular}

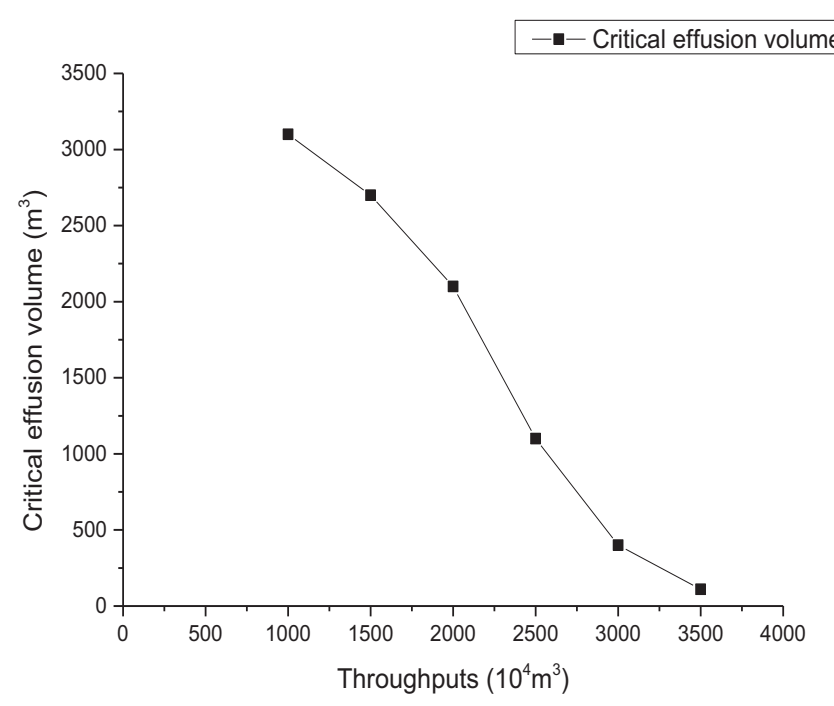

Fig. (12). Relationship between throughput and critical effusion volume in the pipeline.

As shown in Fig. (12), for the range of throughput used in the calculatons, the largest effusion volume is $3100 \mathrm{~m}^{3}$ corresponding to the throughput of $1000 \times 10^{4} \mathrm{~m}^{3} / \mathrm{d}$. However, the critical effusion volume decreases with increasing throughput.

When the throughput increases to $3500 \times 10^{4} \mathrm{~m}^{3} / \mathrm{d}$ which is close to the design throughput, the effusion volume is $110 \mathrm{~m}^{3}$, which is the smallest effusion volume. This is due to the big difference between the actual operating pressure and the maximum allowable operating pressure for smaller throughput. Thus, the big pressure difference can prevent the formation of effusion, so more effusion can be accommodated. However, when the throughput is high, the actual operating pressure is close to the designed pressure of the pipeline, so the critical effusion volume in the pipeline is small.

Therefore, it is recommended that the throughput in the pipeline be increased so as to keep the critical effusion volume small.

\section{CONCLUSION}

Based on the liquid holdup and the capacity of the gas to carry liquid, the effusion volume has been determined. During the process of the natural gas transmission, the lower the temperature and pressure, the higher is the liquid holdup. However, the capacity of the gas to carry liquid is governed by the throughput. According to the model, the critical effusion volume in the China-Burma natural gas pipeline based on OLGA has been calculated. The results show that the effusion volume in the pipeline is mainly distributed near the pipe outlet. The critical effusion volume decreases with increasing throughput. By increasing the throughput, this can reduce the number of pigging measures and the 
corresponding pigging risk. This has a significant effect on the determination of the pigging cycle.

\section{CONFLICT OF INTEREST}

The authors confirm that this article content has no conflict of interest.

\section{ACKNOWLEDGEMENTS}

Declared none.

\section{REFERENCE}

[1] J. Zhang, J.F. Tang, and Y.X. Liu, "Influences of condensate on gas transmission line’s flow parameter", Natural Gas Industry, vol. 26, pp. 118-121, 2006.

[2] Y.G. Xie, J.Z. Hu, and J.Y. Zhou, "Calulation of pipeline effusion quantity and foam discharging technologies in the West Trunk Line I of the Zizhou Gas Field, Ordos Basin", Natural Gas Industry, vol. 34, pp. 98-103, 2014.

[3] S.D. Chen, S.Y. Yang, and J.M. Fu, "Influencing factors and determination methods of gas pipeline pigging cycle", Oil \& Gas Storage And Transportation, vol. 32, pp. 390-394, 2013.

[4] J.S. Zhao, L. Yang, and M.J. Wei, "Determination of pigging cycle for gas transmission pipeline in Sulige Gas filed", Oil \& Gas Storage And Transportation, vol. 30, pp. 71-72, 2011

[5] C.J. Li, G. Liu, J. Wang, and K.X. Liao, "The study of submarine pipeline spill volume prediction based on OLGA", International Journal of Applied Environmental Science, vol. 9, pp. 1219-1236, 2014.

[6] K.H. Bendlksen, M. Dag, and M. Randl, "The dynamic two-fluid model OLGA: Theory and application", SPE Production Engineering, vol. 6, pp. 171-179, 1991.

[http://dx.doi.org/10.2118/19451-PA]

[7] X.W. Chao, Y.X. Li, and S.C. Feng, "Development of Pinghu- Shanghai gas pipeline simulator", Oil \& Gas Storage And Transportation, vol. 16, pp. 16-21, 1997.

[8] G. Xiong, W.L. Wu, and W.A. Ji, "Failure analysis of sour natural gas gathering and transportation pipeline", Chemical Engineering of Oil \& Gas, vol. 41, pp. 99-101, 2012.

[9] L.E. Gomez, O. Shonham, and Z. Schmidt, "A unified mechanistic model for steady-state two-phase flow in wellbores and pipelines", In: SPE Annual Technical Conference and Exhibition, 3-6 October, Houston, Texas, 1999. [http://dx.doi.org/10.2118/56520-MS]

[10] J. Xiao, O. Shonham, and J. P. Brill, "A comphensive mechanistic model for two-phase flow in pipelines", In: SPE Annual Technical Conference and Exhibition, 23-26 September, New Orleans, Louisiana, 1990. [http://dx.doi.org/10.2118/20631-MS]

(C) Liu et al. ; Licensee Bentham Open

This is an open access article licensed under the terms of the Creative Commons Attribution-Non-Commercial 4.0 International Public License (CC BY-NC 4.0) (https://creativecommons.org/licenses/by-nc/4.0/legalcode), which permits unrestricted, non-commercial use, distribution and reproduction in any medium, provided the work is properly cited. 